\title{
Modulation of Cortisol Responses to an Acute Stressor in Zebrafish Visually Exposed to Heterospecific Fish During Development
}

\author{
Murilo S. Abreu, Thiago A. Oliveira, Gessi Koakoski, Rodrigo E. Barreto, and Leonardo J.G. Barcellos ${ }^{1,3}$
}

\begin{abstract}
Studies regarding predator-prey relationships have often focused on prey assessment and the responses to predation risk, but few have verified the relationship in the presence or absence of visual contact with a predator (e.g., tiger oscar, Astronotus ocellatus) or a nonpredator (e.g., goldfish, Carassius auratus) during the developmental phase, which could alter several physiological and neuroendocrine mechanisms in adulthood. Herein, we determined responses to physical (chasing with a net) and biological stressors (visualization to predator) in adult zebrafish raised in visual contact with a predator or nonpredator fish. We demonstrated that adult naive zebrafish show a more intense cortisol stress response than fish housed in visual contact with the stimulus fish (predator or nonpredator) when larvae, and that this alteration is related with movement specificity of the stimulus fish.
\end{abstract}

Keywords: stress, prey-predator relationship, behavior, HPI axis, visual stimulus

\section{Introduction}

J NDividuals of The SAME SPECIES do not respond to environmental challenges in the same way. When facing a predator, for example, some individuals quickly exhibit an intense stress response, during which breathing rate increases and glucocorticoids are released, whereas other individuals may exhibit a weaker physiological response or recover faster when the stressor is removed. ${ }^{1,2}$ Furthermore, predation pressure varies locally, which provides opportunities for local adaptations in the display of antipredator behaviors and stress responses. ${ }^{3,4}$ Development in areas with high predation pressure can modulate the behavior of the prey; experiencing multiple nonlethal exposures to predators could alter the magnitude of avoidance and anticipatory defensive responses by prey species. ${ }^{5}$

In fact, predation risk represents a stressor for prey fish, leading to an increase in cortisol levels. ${ }^{6,7}$ In this context, although short-term increases in cortisol during prey-predator interactions are potentially adaptive (as shown in lizards ${ }^{8}$ and fish ${ }^{9}$ ), chronically elevated cortisol levels may have adverse effects. ${ }^{10}$ Exposure of fish to a chronic stressor can alter the capacity to respond to an additional acute stressor. ${ }^{11}$ In some fish species, chronic stress does not influence the acute response to an additional stressor, ${ }^{12}$ but in other species the acute response is abolished ${ }^{13}$ or reduced. ${ }^{14}$ A similar approach has been reported in relation to the prey hypothalamic-pituitary-interrenal (HPI) axis activation by predator presence, which inhibits foraging and reproduction of prey fish. ${ }^{15}$ Besides, the impacts of zebrafish development in isolated or grouped housed conditions are well known ${ }^{16}$; however, the constant presence of a risky situation during development remains to be explored. Thus, could continuous visual nonlethal exposure to a predator in early ontogeny lead to a decreased cortisol stress response in adults? We tested this question using, as the experimental model, zebrafish (Danio rerio), a fish species that presents antipredator and stress responses in the context of prey-predator relationships. ${ }^{6,7,17}$ We used visual exposure to a predator as the stimulus because it is a stressor for zebrafish.

\section{Materials and Methods \\ Experimental animals}

Male and female adult zebrafish $(\approx 5 \mathrm{~cm})$, wild-type shortfin strain, were placed in breeding tanks specifically designed for the collection of eggs that sank to the bottom of the tank. This was achieved by inserting a grid with a mesh size of

\footnotetext{
${ }^{1}$ Programa de Pós-Graduação em Farmacologia, Universidade Federal de Santa Maria (UFSM), Cidade Universitária, Santa Maria, Brazil.

${ }^{2}$ Departamento de Fisiologia, Instituto de Biociências, Universidade Estadual Paulista (UNESP), Centro de Aquicultura da UNESP, Botucatu, Brazil.

${ }^{3}$ Programa de Pós-Graduação em Bioexperimentação, Universidade de Passo Fundo (UPF), Hospital Veterinário, Passo Fundo, Brazil.
} 
$1 \times 1 \mathrm{~mm}$ at the bottom of the breeding tank. In the morning, adult animals were removed and the embryos collected by siphoning. The fertilized eggs were transferred to plates, incubated at $28^{\circ} \mathrm{C}$, and monitored daily for up to 3 days postfertilization for further separation into experimental groups. After, larvae developed in aquarium $(100 \times 50 \times 50$ $\mathrm{cm}$ [width $\times$ depth $\times$ height]) divided into two equally sized (one side zebrafish / other side predator, nonpredator, or without any visual contact with stimulus fish [predator or nonpredator]). The fish remained for the visual stimulation period glass $100 \times 50 \times 50 \mathrm{~cm}($ width $\times$ depth $\times$ height $)$ divided by a glass in two equally sized (one side zebrafish/other side predator or nonpredator). Fish were fed twice a day (09:00 and 16:00 h), until apparent satiety, with commercial flakes (TetraMin ${ }^{\circledR}$; Tetra, Melle, Germany). This study was approved by the Ethics Commission for Animal Use (CEUA) at Universidade de Passo Fundo, UPF, Passo Fundo, RS, Brazil (Protocol No. 3/2014) and performed in full compliance with the guidelines of Conselho Nacional de Controle de Experimentacão Animal-CONCEA ("National Committee for Controlling of Animal Experimentation”).

\section{Phase I: response to physical stressor after the development period}

Three days after hatching, zebrafish larvae remained on the opposite side of the visual stimulus until the end of the study, which were distributed into three groups: group 1, named "normal housing" stress $(\mathrm{NH})$, consisted of zebrafish reared with contact only of conspecifics in the same situation without any visual contact with stimulus fish (predator and/or nonpredator); group 2, named "predator housing" (PH), consisted of zebrafish reared for 90 days with visual contact with a

A

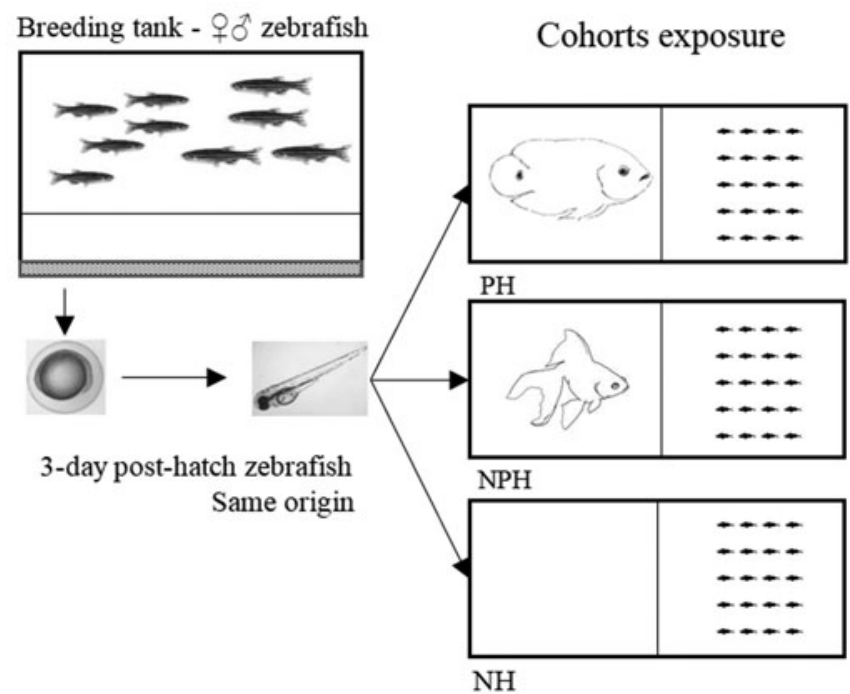

predator (tiger oscar, Astronotus ocellatus, $\approx 25 \mathrm{~cm}$ ); and group 3, named "nonpredator housing" (NPH), consisted of zebrafish reared with visual contact with a large nonpredatory fish (goldfish, Carassius auratus, $\approx 18 \mathrm{~cm}$ ) (Fig. 1A).

At 90-day rearing period, 10 fish from the $\mathrm{NH}, \mathrm{PH}$, and $\mathrm{NPH}$ were captured and immediately euthanized for wholebody cortisol determination (see S- in Fig. 1B); besides, 10 fish from each group ( $\mathrm{NH}, \mathrm{PH}$, and $\mathrm{NPH}$ ) received an acute stress challenge, consisting of $120 \mathrm{~s}$ of chasing with a net pen, and after $15 \mathrm{~min}$ of stress challenge were captured and immediately euthanized for whole-body cortisol determination (see $\mathrm{S}+$ in Fig. 1B). In this 90-day period, no significant mortality was verified with the same survival rates (about $75 \%$ ) of the reproductive routine of the laboratory. The experiments were conducted in duplicate.

During the developmental period (90 days), all aquaria were monitored for the following variables: temperature $\left(27^{\circ} \mathrm{C} \pm 1^{\circ} \mathrm{C}\right), \mathrm{pH}(7 \pm 0.2)$, dissolved oxygen $(6.7 \pm 0.3 \mathrm{mg}$ $\left.\mathrm{L}^{-1}\right)$, total ammonia $\left(0.01 \mathrm{mg} \mathrm{L}^{-1}\right)$, total hardness $\left(6 \mathrm{mg} \mathrm{L}^{-1}\right)$, and alkalinity $\left(22 \mathrm{mg} \mathrm{L}^{-1}\right.$ of $\left.\mathrm{CaCO}_{3}\right)$. The fish were maintained under natural photoperiod ( $\sim 14 \mathrm{~h}$ light: $10 \mathrm{~h}$ dark). There was no difference in mortality during ontogenetic development among the groups.

\section{Phase II: response to biological stress (visualization stimulus predator)}

In Phase II, after the 100-day rearing, 10 fish in NH control, PH stress, and NPH stress groups were exposed to visual stimulation with the predatory fish for $60 \mathrm{~min}$. After which, they were captured and immediately euthanized for wholebody cortisol determination (Fig. 1C). During these 10 days, fish did not visualize any stimulus fish.
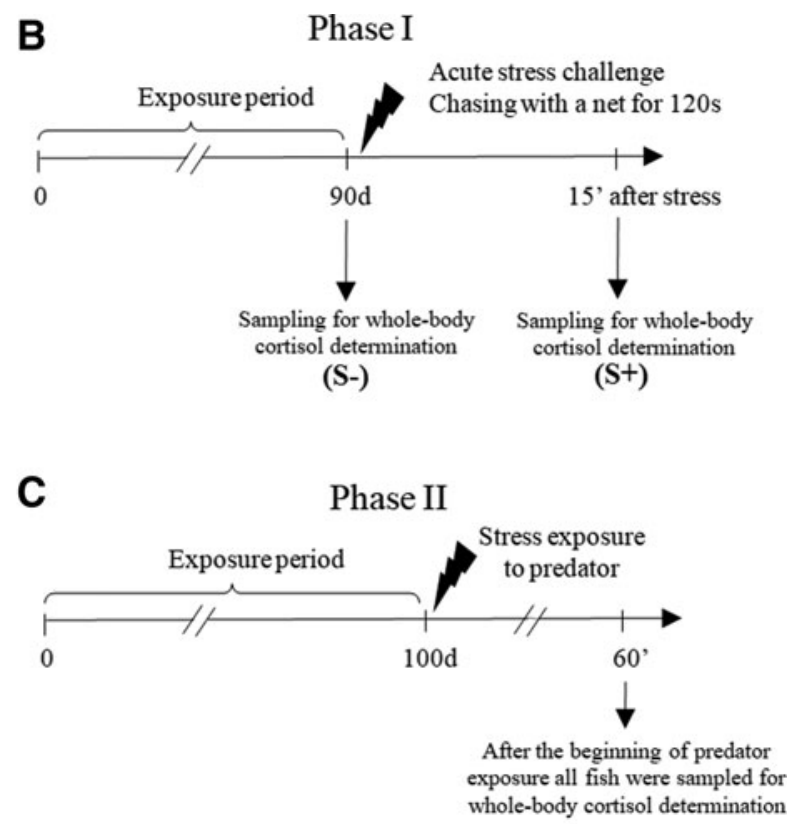

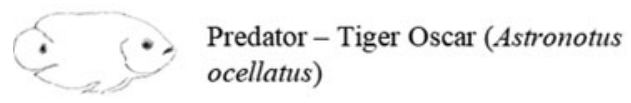

Non Predator - Goldfish (Carasssius auratus)

FIG. 1. Schematic representation of the experimental design. (A) Cohort exposure, (B) schematic representation Phase I (S-, without stressor stimulus; S+, with stressor stimulus), (C) schematic representation Phase II. NH, normal housing stress; NPH, nonpredator housing; PH, predator housing. 
To encourage predatory behavior, feeding of the predator was suspended for $24 \mathrm{~h}$ before exposing it to the zebrafish. The same procedure was conducted for the nonpredatory goldfish. To avoid the influence of circadian rhythms on cortisol secretion, all samples were collected at the same time of day (03:00 PM).

\section{Phase III: additional experiment-predator} and nonpredator behavior visualizing a shoal of prey fish and an empty aquarium

This phase was conducted to evaluate the movement and location of both predator and nonpredator stimulus fish in visual contact with a shoal of zebrafish or an empty aquarium (Fig. 2). The predator and nonpredator behavior was videotaped for $60 \mathrm{~min}$, and we evaluated locomotion parameters. The aquarium was virtually divided for behavioral analysis into six compartments, as shown in Figure 2. The predator and nonpredator were filmed using a Logitech HD Webcam C525 camera (Logitech, Romanel-sur-Morges, Switzerland) during the 60-min exposure period to the shoal of zebrafish or an empty tank. The evaluated variables were total distance in aquarium, mean swimming speed, maximum swimming speed, turn angle, number of crossings among quadrants, and time in each quadrant. The videos were analyzed using ANYmaze ${ }^{\circledR}$ software (Stoelting Co.).

\section{Whole-body cortisol determination}

The Phase I and Phase II fish were captured and immediately euthanized, followed by storage at $-20^{\circ} \mathrm{C}$ until cortisol extraction. Whole-body cortisol was extracted using the method described by Sink et al. ${ }^{19}$ The accuracy of cortisol detection was tested by calculating recovery from samples treated with known amounts of cortisol $(50,25$, and $12.5 \mathrm{ng}$ $\left.\mathrm{mL}^{-1}\right)$. The mean detection accuracy of treated samples was 94.4\%. Whole-body cortisol levels were measured using a commercially available enzyme-linked immunosorbent assay kit (EIAgenTMCORTISOL test; BioChem ImmunoSystems).

\section{Statistics}

The normality of the samples was determined using the Kolmogorov-Smirnov test. Homogeneity of variances was determined using Hartley's test. We applied in Phase I a two-way analysis of variance (ANOVA) followed by the Tukey post hoc test, considering visual stimulation during development and stressor stimulus as independent factors. Because these premises were not achieved for Phase II, we applied the Kruskal-Wallis test (nonparametric ANOVA) followed by Dunn's multiple comparison test to compare data in experiment. In Phase III, for the evaluation of predator and nonpredator behavior, we used a one-way ANOVA followed by a post hoc Tukey's test. Significant differences were set at $p<0.05$.

\section{Results}

Phase l: response to physical stressor after the development period

There was a strong significant interaction between visual stimulation during development and stressor stimulus $\left(\mathrm{F}_{2,43}=19.85 ; p<0.0001\right)$ and significant single effects of stressor stimulus $\left(\mathrm{F}_{1,43}=158.3 ; p<0.0001\right)$ and visual stimulation during development $\left(\mathrm{F}_{2,43}=17.16 ; p<0.0001\right)$. Comparing the treatments, fish raised seeing a predator $(\mathrm{PH})$, nonpredator $(\mathrm{NPH})$, or in an aquarium without stimulation $(\mathrm{NH})$ did not show differences in their baseline cortisol levels (Fig. 3A). However, when challenged with acute stress, the predator $(\mathrm{PH})$ and aquarium without stimulation $(\mathrm{NH})$ groups presented higher cortisol levels than the nonpredator (NPH) group (Fig. 3A).

\section{Phase II: response to biological stress (visualization stimulus predator)}

The Kruskal-Wallis test revealed a significant difference between groups $(p=0.0003, K=16.44)$. In the response to biological stress of visualization to predator, fish from the predator $(\mathrm{PH})$ and aquarium without stimulation $(\mathrm{NH})$ groups

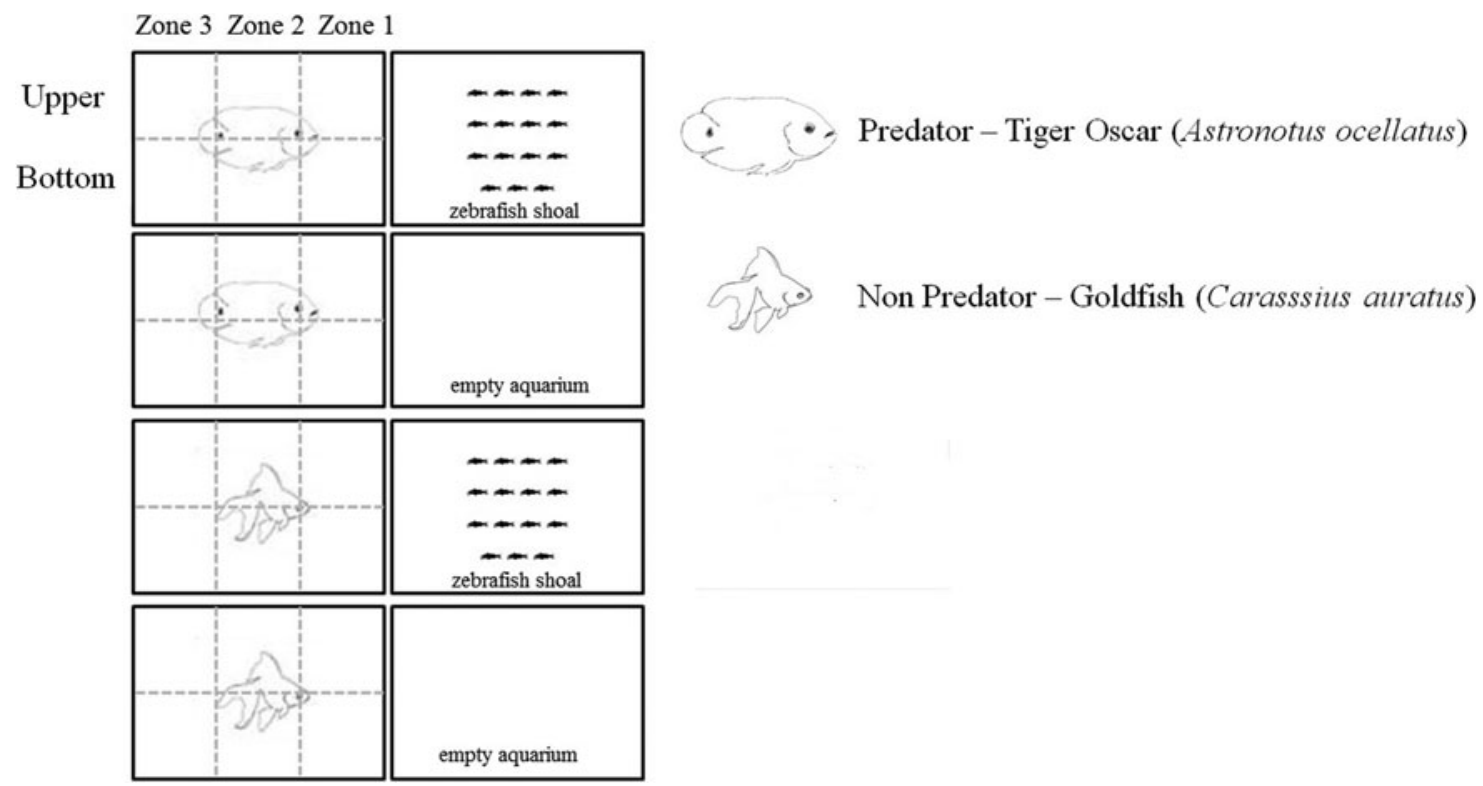

FIG. 2. Schematic of the experimental protocol for predator and nonpredator behavior analysis. 

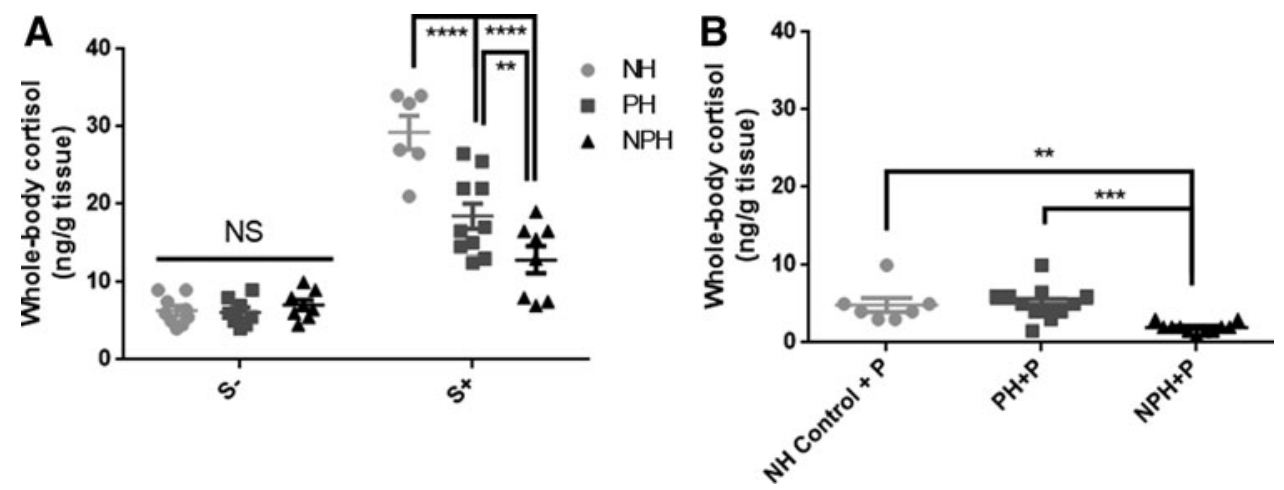

FIG. 3. Whole-body cortisol concentrations in fish reared for 90 days while viewing a stimulus fish and after acute stress (Phase I, A); whole-body cortisol concentrations in fish re-exposed to a predator for 60 min (Phase II, B). Data are expressed as mean \pm SEM $(n=10)$, Phase I (two-way ANOVA test), and Phase II (Kruskal-Wallis test) $(* * p<0.01 ; * * * p<0.001$, and $* * * * p<0.0001)$. ANOVA, analysis of variance; NS, not significant.

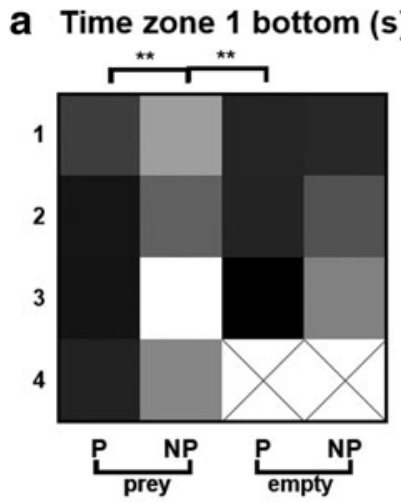

d Time zone 1 upper (s)
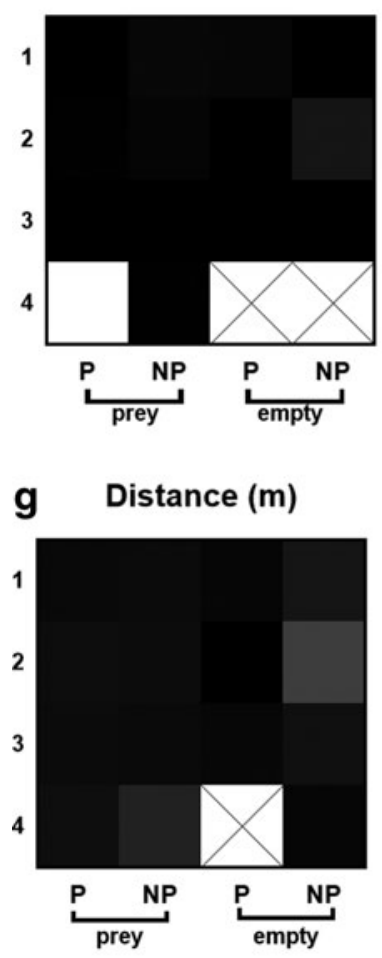

b Time zone 2 bottom (s)

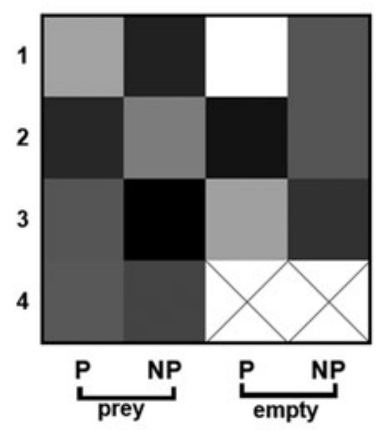

e Time zone 2 upper (s)

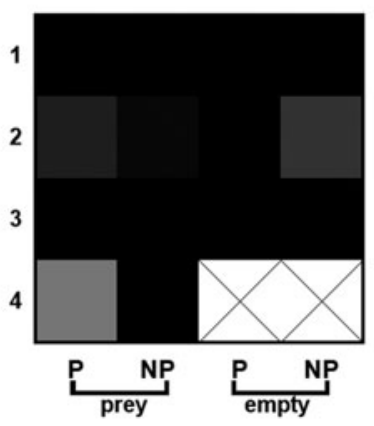

h Crossings (n)

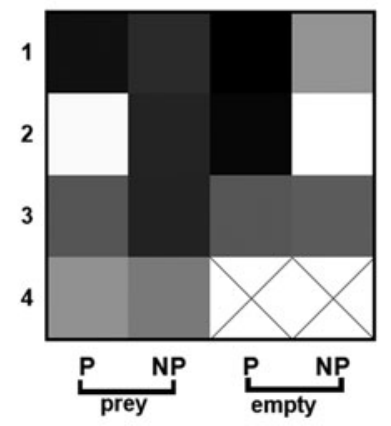

C Time zone 3 bottom (s)

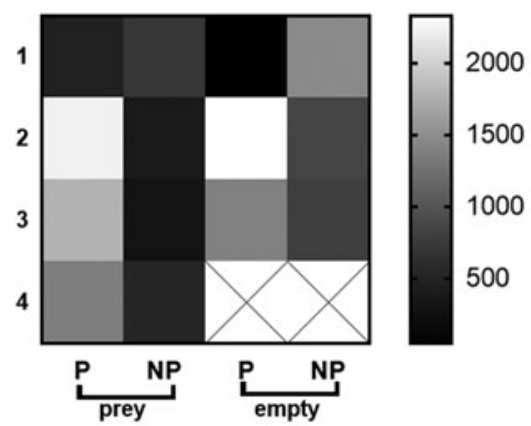

f Time zone 3 upper (s)

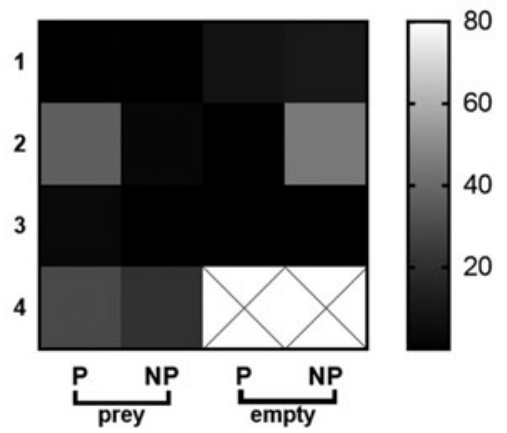

i Mean speed $(\mathrm{m} / \mathrm{s})$
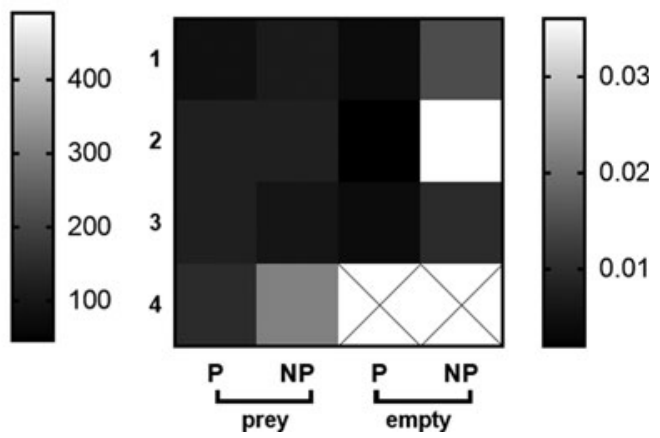

FIG. 4. Locomotion parameters for predator and nonpredator behavior analysis exposed to zebrafish shoal and empty aquarium. (a) Time in zone 1 bottom, (b) time in zone 2 bottom, (c) time in zone 3 bottom, (d) time in zone 1 upper, (e) time in zone 2 upper, (f) time in zone 3 upper, (g) distance, (h) crossing, (i) mean speed. Data are expressed as heat map and oneway ANOVA $(* * p<0.01)$. 
presented higher cortisol levels following $60 \mathrm{~min}$ of visual exposure to a predator than did fish from the nonpredator (NPH) group (Fig. 3B).

\section{Phase III: additional experiment-predator and nonpredator behavior visualizing a shoal of prey fish and an empty aquarium}

In the behavioral analysis of predator and nonpredator viewing the zebrafish shoal and the empty aquarium, the nonpredator exhibited more time in zone 1 bottom than the predator $\left(\mathrm{F}_{3,11}=8.762 ; p=0.0038\right.$; Fig. 4a). No difference was found for any other behavioral variable.

\section{Discussion}

Here we demonstrated that naive zebrafish show a more intense cortisol stress response than fish exposed to a stimulus fish. We expected that the predator only would modulate the acute stress response in zebrafish, but it also occurred when the visual stimulus was a nonpredatory fish. Why did this occur? To answer this question, we conducted an additional experiment (Phase III, Fig. 2), in which we attempted to discriminate between behaviors of the nonpredator and predator fish in visual contact with a shoal of zebrafish. Because the nonpredatory fish spent much of its time at the same height in the water column as the zebrafish shoal, we hypothesized that this behavior was the key factor that modulated the zebrafish cortisol response when they faced this harmless fish. This indicated that stimulus fish for the NPH and $\mathrm{PH}$ group perceived the presence of a shoal and behaved differently, one approaching the shoal (NPH) and the other $(\mathrm{PH})$ moving away from the shoal. We also suggest that because zebrafish received a visual stimulus only (with no other sensory cues), the visual stimulus may have led to the "misinterpretation" of the stimulus fish, and the harmless fish was considered a potential threat. However, this was not the case in another study utilizing these two species (zebrafish and goldfish). ${ }^{20}$

The NPH zebrafish that developed in the presence of a daily stimulus, visual contact with a fish larger than itself, may have perceived it as a risk; since exposure to objects perceived as "risky" may cause higher stress response, such as increased stress levels in nurses by working with sharp objects. $^{21}$ Besides, Luca and Gerlai ${ }^{22}$ found that the strongest fear responses were induced by images with the largest point size (among images of a sympatric predator, the Indian leaf fish, or a bird silhouette) shown to zebrafish, which were believed to interpret these stimuli as fast-approaching objects that could attack them. In addition, zebrafish preferred individuals that exhibited characteristics similar to their own (i.e., they exhibited a preference for conspecifics ${ }^{23,24}$ ). Thus, it is plausible that the heterospecific, although harmless, goldfish was perceived by the zebrafish as a threat, which led to a similar response as that obtained when zebrafish were exposed to the predatory tiger oscar. Besides, zebrafish identify the predator and nonpredator elevating cortisol levels, as well as zebrafish remain for a longer time in the bottom zone of aquarium when in visual contact with stimulation (predator and nonpredator). ${ }^{25}$

In addition, repeated stress responses in shoals could have a cumulative effect, because zebrafish housed together have a greater response to stress than isolated zebrafish, ${ }^{26}$ which leads to exhaustion of the HPI axis. Plasma cortisol decreased steadily over time in stressed fish, which is indicative of exhaustion, and the lack of the potential for an endocrine response to stressors through this stress axis. ${ }^{27}$ This was confirmed by a lower cortisol response to the novel stressor at the end of the stress period in chronically stressed (3 weeks) fish than in fish from the control group. ${ }^{27}$

Our study is important to understanding the breeding, development, and housing of fish that will be used experimentally because development in adverse situations can lead to the lack of normal responses to stimuli. Health management in aquaculture, laboratory manipulation may be associated with responses to stressful stimuli; this stimulus can be not only a stimulating predator but also management, machinery, and the presence of humans, which is usually indicative of prolonged, repeated, or unavoidable stresses. ${ }^{28}$ These include both direct and indirect effects of poor adaptation to chronic, long-term stress, such as reduced growth, ${ }^{29}$ suppressed reproductive function, ${ }^{30}$ decreased immune function, ${ }^{31}$ and resistance to disease. ${ }^{32}$

\section{Acknowledgments}

The study was funded by the Universidade de Passo Fundo, and CNPq L.J.G.B. and R.E.B. hold CNPq research fellowships (301992/2014-2 and 302719/2013-0, respectively).

\section{Disclosure Statement}

No competing financial interests exist.

\section{References}

1. Koolhaas JM, Korte SM, De Boer SF, Van Der Vegt BJ, Van Reenen CG, Hopster H, et al. Coping styles in animals: current status in behavior and stress-physiology. Neurosc Biobehav Rev 1999;23:925-935.

2. Wada H, Salvante KG, Stables C, Wagner E, Williams TD, Breuner CW. Adrenocortical responses in zebra finches (Taeniopygia guttata): individual variation, repeatability, and relationship to phenotypic quality. Horm Behav 2008; 53:472-480.

3. Bell AM, Henderson L, Huntingford FA. Behavioral and respiratory responses to stressors in multiple populations of three-spined sticklebacks that differ in predation pressure. J Comp Physiol B 2010;180:211-220.

4. Magurran AE, Seghers BH, Carvalho GR, Shaw PW. Evolution of adaptive variation in antipredator behavior. Mar Behav Physiol 1993;23:29-44.

5. Gravel MA, Suski CD, Cooke SJ. Behavioral and physiological consequences of nest predation pressure for larval fish. Behav Ecol 2011;22:510-219.

6. Barcellos LJG, Ritter F, Kreutz LC, Quevedo RM, Silva LB, Bedin AC, et al. Wholebody cortisol increases after direct and visual contact with the predator in zebrafish, Danio rerio. Aquaculture 2007;272:774-778.

7. Barcellos LJG, Koakoski G, da Rosa JGS, Ferreira D, Barreto RE, Giaquinto PC, et al. Chemical communication of predation risk in zebrafish does not depend on cortisol increase. Sci Rep 2014;4:5076. 
8. Thaker M, Lima SL, Hews DK. Acute corticosterone elevation enhances antipredator behaviors in male tree lizard morphs. Hormon Behav 2009;56:51-57.

9. Barreto RE, Barbosa-Junior A, Urbinati EC, Hofmann A. Cortisol influences the antipredator behavior induced by chemical alarm cues in the frillfin goby. Hormon Behav 2014;128:394-400.

10. Sapolsky RM. Endocrinology of the stress-response. In: Behavioral Endocrinology. 2nd ed. pp. 409-450, Becker JB, Breedlove SM, Crews D, McCarthy MM (eds). The MIT Press, Cambridge, MA, 2002.

11. McEwen BS, Seeman T. Protective and damaging effects of mediators of stress: elaborating and testing the concepts of allostasis and allostatic load. Ann NY Acad Sci 1999; 896:30-47.

12. Barcellos LJG, Kreutz LC, Quevedo RM. Previous chronic stress does not alter the cortisol response to an additional acute stressor in jundiá (Rhamdia quelen, Quoy and Gaimard) fingerlings. Aquaculture 2006;253:317-321.

13. Grassie C, Braithwaite VA, Nilsson J, Nilsen TO, Teien $\mathrm{HC}$, Handeland SO, et al. Aluminum exposure impacts brain plasticity and behavior in Atlantic salmon (Salmo salar). J Exp Biol 2013;216:3148-3155.

14. Barcellos LJG, Nicolayewisky S, Souza SMG, Lulhier F. Plasmatic levels of cortisol in the response to acute stress in Nile tilapia, Oreochromis niloticus (L.), previously exposed to chronic stress. Aqua Res 1999;30:437-444.

15. Harris BN, Carr JA. The role of the hypothalamuspituitary-adrenal/interrenal axis in mediating predatoravoidance trade-offs. Gen Comp Endocrinol 2016;231: 110-142.

16. Keck VA, Edgerton DS, Hajizadeh S, Swift LL, Dupont WD, Lawrence C, et al. Effects of habitat complexity on pair-housed zebrafish. J Am Assoc Lab Anim Sci 2015;54: 378-383.

17. Bass SLS, Gerlai R. Zebrafish (Danio rerio) responds differentially to stimulus fish: the effects of sympatric and allopatric predators and harmless fish. Behav Brain Res 2008;186:107-117.

18. Barreto RE, Luchiari AC, Marcondes AL. Ventilatory frequency indicates visual recognition of an allopatric predator in naïve Nile tilapia. Behav Processes 2003;60:235-239.

19. Sink TD, Kumaran S, Lochmann RT. Development of a whole-body cortisol extraction procedure for determination of stress in golden shiners, Notemigonus crysoleucas. Fish Physiol Biochem 2007;33:189.

20. Oliveira TA, Koakoski G, Kreutz LC, Ferreira D, Rosa JGS, Abreu MS, et al. Alcohol impairs predation risk response and communication in zebrafish. PLoS One 2013;8: e75780.

21. Moayed MS, Mahmoudi H, Ebadi A, Sharif Nia H. Stress and fear of exposure to sharps in nurses. Iran J Psychiatry Behav Sci 2016;10:e3813.
22. Luca RM, Gerlai R. In search of optimal fear inducing stimuli: differential behavioral responses to computer animated images in zebrafish. Behav Brain Res 2012;226:66-76.

23. Saverino C, Gerlai R. The social zebrafish: behavioral responses to conspecific, heterospecific, and computer animated fish. Behav Brain Res 2008;191:77-87.

24. Moura CA, Luchiari AC. Time-place learning in the zebrafish (Danio rerio). Behav Proces 2016;128:64-69.

25. Oliveira TA, Idalencio R, Kalichack F, da Rosa JGS, Koakoski G, Abreu MS, et al. Stress responses to conspecific visual cues of predation risk in zebrafish. PeerJ 2017; 5:e3739.

26. Giacomini ACVV, Abreu MS, Koakoski G, Idalêncio R, Kalichak F, Oliveira TA, et al. My stress, our stress: blunted cortisol response to stress in isolated housed zebrafish. Phys Behav 2015;139:182-187.

27. Madaro A, Olsen RE, Kristiansen TS, Ebbesson LOE, Nilsen TO, Flik G, et al. Stress in Atlantic salmon: response to unpredictable chronic stress. J Exp Biol 2015;218:2538-2550.

28. Barton BA. Stress in fishes: a diversity of responses with particular reference to changes in circulating corticosteroids. Integr Comp Biol 2002;42:517-525.

29. Pankhurst NW, Van der Kraak G. Effects of stress on reproduction and growth. In: Fish Stress and Health in Aquaculture. Iwama G, Pickering A, Sumpter J, Schreck C (eds). pp. 73-94, Cambridge University Press, Cambridge, 1997.

30. Schreck CB, Contreras-Sanchez W, Fitzpatrick MS. Effects of stress on fish reproduction, gamete quality, and progeny. Aquaculture 2001;197:3-24.

31. Einarsdottir IE, Nilssen KJ, Iversen M. Effects of rearing stress on Atlantic salmon (Salmo salar L.) antibody response to a non-pathogenic antigen. Aqua Res 2000;31: 923-930.

32. Balm PHM. Immune-endocrine interactions. In: Fish Stress and Health in Aquaculture. Iwama G, Pickering A, Sumpter J, Schreck C (eds), pp. 195-222, Cambridge University Press, Cambridge, United Kingdom, 1997.

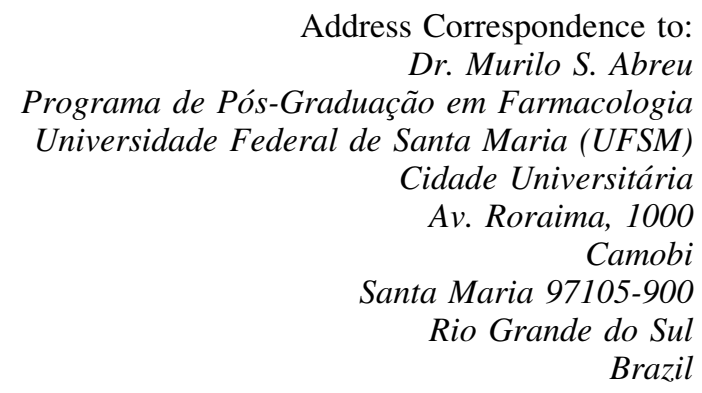

E-mail: abreu_murilo@hotmail.com 